\title{
Propulsion Powertrain Real-Time Simulation Using Hardware-in- the-Loop (HIL) for Aircraft Electric Propulsion System
}

\author{
Benjamin B. Choi ${ }^{1}$ and Gerald V. Brown ${ }^{2}$ \\ National Aeronautics and Space Administration, Glenn Research Center, Cleveland, Ohio, 44135
}

\begin{abstract}
It is essential to design a propulsion powertrain real-time simulator using the hardwarein-the-loop (HIL) system that emulates an electrified aircraft propulsion (EAP) system's power grid. This simulator would enable us to facilitate in-depth understanding of the system principles, to validate system model analysis and performance prediction, and to demonstrate the proof-of-concept of the EAP electrical system. This paper describes how subscale electrical machines with their controllers can mimic the power components in an EAP powertrain. In particular, three powertrain emulations are presented to mimic 1) a gas turboshaft engine driving a generator, consisting of two permanent magnet (PM) motors with brushless motor drives, coupled by a shaft, 2) a motor driving a propulsive fan, and 3) a turbo-shaft engine driven fan (turbofan engine) operation. As a first step towards the demonstration, experimental dynamic characterization of the two motor drive systems, coupled by a mechanical shaft, were performed. The previously developed analytical motor models $^{1}$ were then replaced with the experimental motor models to perform the real-time demonstration in the predefined flight path profiles. This technique can convert the plain motor system into a unique EAP power grid emulator that enables rapid analysis and realtime simulation performance using hardware-in-the-loop (HIL).
\end{abstract}

\section{Introduction}

$\mathrm{T}$ he NASA Glenn Research Center (GRC), in collaboration with the aerospace industry and academia, has been developing technologies to make large reductions in aircraft energy use, emissions, and noise by 2040 . One concept is a future electric aircraft employing a Turbo-electric Distributed Propulsion (TeDP) system (see Figure 1) in full support of Electrified Aircraft Propulsion (EAP) system. It is essential to design a subscale system to emulate the TeDP power grid, which would enable rapid analysis and demonstration of the proof-of-concept of the TeDP electrical system. This paper describes how small electrical machines with their controllers can mimic all the components in a TeDP powertrain.

The whole system model in MATLAB/Simulink was first developed and tested in simulation ${ }^{1}$, and the simulation results showed that system dynamic characteristics could be implemented by using closed-loop control of the electric motor drive systems. Then, we designed subscale experimental system to imitate the entire power system from the turbine engine to the propulsive fans. However, this paper focuses on the methodology how the subscale electrical machines with their controllers can mimic the power components in an EAP powertrain using hardwarein-the-loop (HIL).

First, a system that consists of two permanent magnet (PM) motors with brushless motor drives, coupled by a shaft, was constructed to emulate 1) a gas turboshaft engine driving a generator. The first motor and its drive system was programmed to mimic the speed-torque characteristics of the gas turbine engine, while the second motor and its drive system act as a generator and produce a torque load on the first motor. Then the same system was used to simulate 2) a motor driving a propulsive fan. Here, the first motor and its drive system was programmed to mimic a wound-rotor synchronous motor. The propulsive fan was emulated by implementing fan maps and flight conditions into the second motor and its drive system, which produce a torque load on the driving motor. Finally, to emulate 3 ) a turbo-shaft engine driven fan (turbofan engine) operation, the same set of motor drive systems was also used. In this case, the first motor and its drive system mimicked the speed-torque characteristics of the gas turbine engine, while the second motor drive system acted as a load torque on the turboshaft motor to emulate the fan maps and

${ }^{1}$ Aerospace Engineer, LMR, Materials and Structures Division, MS 23/3.

${ }^{2}$ Senior Research Engineer, LMR, Materials and Structures Division, MS 49/8. 
flight conditions. As a first step towards the demonstration, experimental dynamic characterization of the two motor drive systems, coupled by a mechanical shaft, were performed. The previously developed analytical motor models ${ }^{1}$ were then replaced with the experimental motor models to perform the real-time demonstration in the predefined flight path profiles (see Figure 2). This technique can convert the plain motor system into a unique EAP power grid emulator that enables real-time simulation performance using hardware-in-the-loop (HIL).

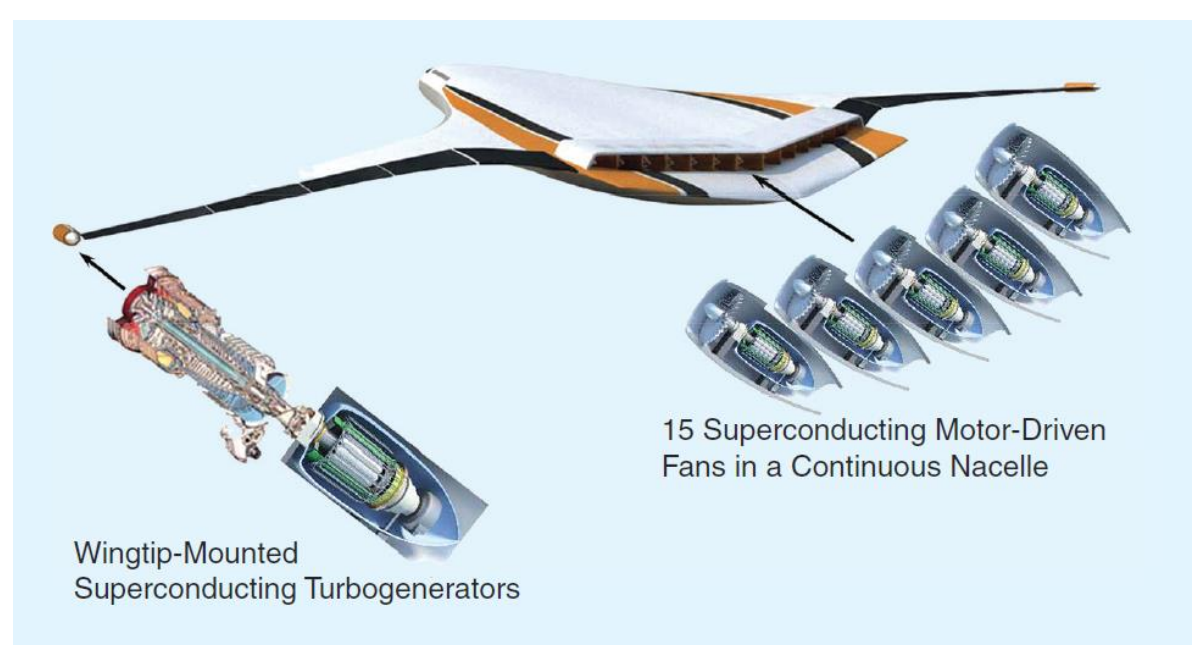

Figure 1. N3-X hybrid wing-body aircraft with a TeDP system.

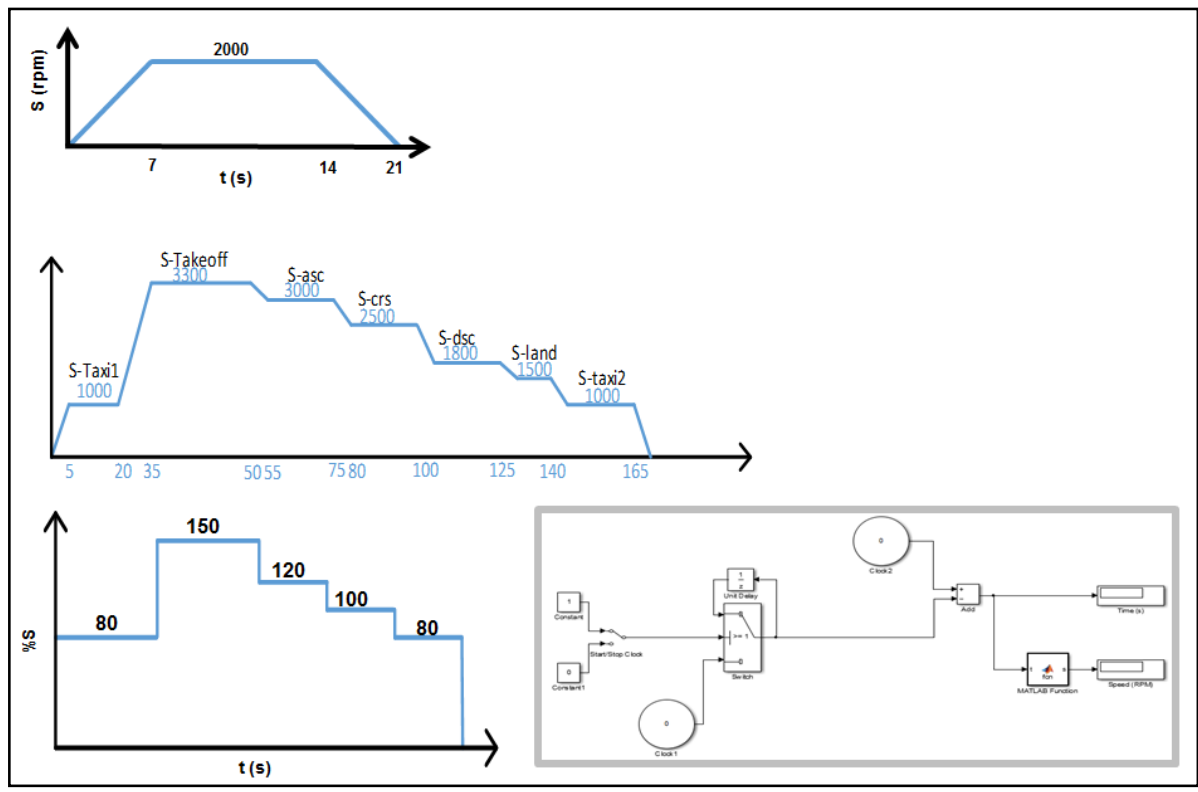

Figure 2. Flight path profile simulation and its implementation to the code.
A turboelectric transmission uses electric generators to convert mechanical energy from a turboshaft engine into electrical energy and electric motors to convert it back into mechanical energy to power the drive shafts of propulsion fans. The world's first turboelectric drive was introduced in the U.S. capital ship design of the USS New Mexico, launched in 1917. The extra weight of the turboelectric plants has made their use prohibitive. But the concept has been revived for future warship design as a way to provide fuel efficient, survivable, and reconfigurable electrical power for propulsion systems. Thus, its application has been extended to ships (steam and, more recently, gas turbines) and some rail locomotives with gas turbines, e.g., the first train à grande vitesse (TGV)French for "high-speed train." An advantage of the turboelectric drive is that it allows the adaptation of high speed turboshaft engines to the slowly rotating propellers or wheels without the need for a heavy and complex gearbox. It also has the advantage of being able to provide electricity to the ship or train's electrical systems,

such as lighting, computers, radar, and communication equipment.

The NASA Glenn Research Center, in support of the Electrified Aircraft Propulsion (EAP) Project, has been conducting research on the evaluation of new technologies to make large reductions in aircraft energy use, emissions, and noise by 2040. One concept is a future hybrid wing-body electric airplane employing a turboelectric distributed propulsion (TeDP) system (Figure 1). This aircraft is powered by two turboshaft engines driving two superconducting generators, which provide electricity to run 15 electric fans mounted on top of the fuselage. The 
primary function of the two wing-tip-mounted superconducting turbogenerators is to make electricity, not thrust. The nozzle of the turbogenerator is sized so there is enough jet velocity during cruising to produce a small amount of net thrust to avoid being a source of drag. The turbogenerators are located on the wingtips so the inlets ingest freestream air. Most of the energy of the gas stream is extracted by the power turbine to drive the generator. The electric power from the turbogenerators is distributed along redundant superconducting electrical cables to an array of superconducting motor-driven fans. The fans are in a continuous array of propulsors spanning the entire upper trailing edge of the center wing-body section. One TeDP system study on this aircraft ${ }^{2,3,4}$, estimated that cryogenic and superconducting turboelectric propulsion systems can be lightweight and highly efficient, resulting in at least $10 \%$ overall net fuel burn savings before iterating the aircraft sizing. Also, Glenn's researchers have been looking at the development of room-temperature high-power density motors. In parallel to and in cooperation with the analytical system modeling and analyses for both cryogenic and room-temperature applications, it is essential to design a subscale system to simulate the TeDP power grid to facilitate in-depth understanding of the system principles and to validate system model analyses and performance predictions. Hence, this paper presents part of research in the development of a propulsion electric grid emulator pursuant to the EAP Project's goal of "greenly" powering future TeDP aircraft.

\section{Experimental Dynamic Characterization of Motor and Its Drive System}

The goal of this section is to develop a methodology by which experimental dynamic characterization of the two motor drive systems, couple by a shaft. The previously developed analytical motor models ${ }^{1}$ were then replaced with the experimental motor models to perform the real-time demonstration in the predefined flight path profiles. This technique can convert the plain motor system into a unique EAP power grid emulator that enables real-time simulation performance using hardware-in-the-loop (HIL).

All power electronics used here to drive the motor systems are from Advanced Motion Controls (AMC). Figure 3 shows the experimental setup of dynamic characterization of the motor drive system. AMC DC power supply provides power to the AMC 3-phase power amplifier with sinusoidal commutation that drives ThinGap brushless motor drive system to generate. AMC shunt regulator is also attached to the terminal in parallel in order to dissipate excessive power generated in the REGEN mode of the motor (e.g., abrupt speed reduction) and to protect power electronics such as power amplifier and power supply. The 3-phase signals from the power amplifier go into the AMC inductor card that adds more inductance to the low inductance motor for stable operation. Finally, the currents from the inductor card go into the first motor drive system that drives the second motor. The second motor is connected to the same AMC 3-phase power amplifier that is also used as an active

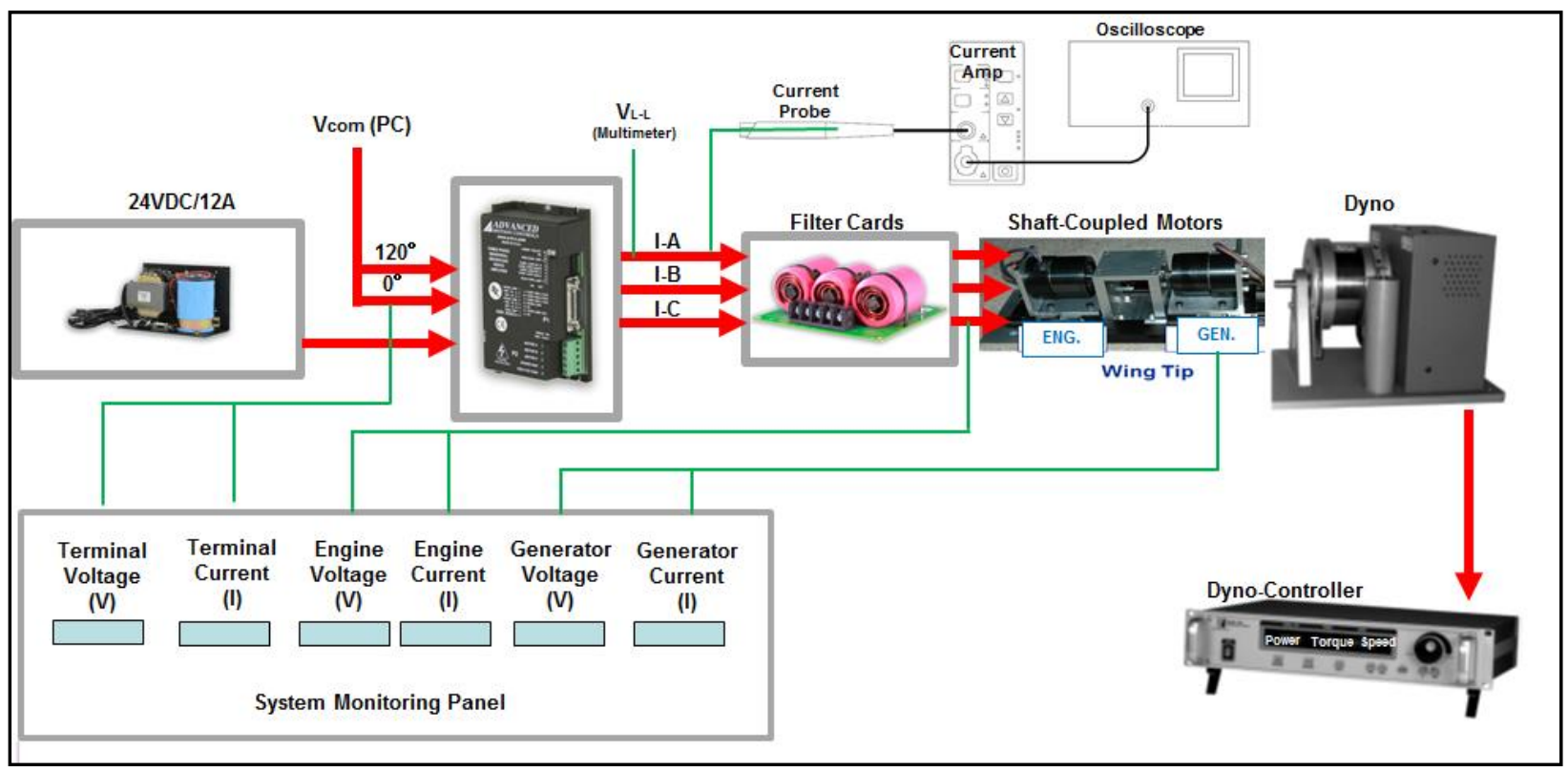

Figure 3. Experimental setup of dynamic characterization of the motor drive system. 
rectifier. This generated DC signal through the active rectifier is the power supply source to drive the other motor drive system such as propulsor (motor-driven fan). A nipple-reducing capacitor is attached to the buss to smooth or even out fluctuation in the generated DC power source. The second motor drive system is connected to the dynamometer and its control system to measure the dynamic torque (or power) versus the rotor speed. As shown in Figure 3, there are three junctions (at terminal, right before the first motor, and right after second motor) where voltage and current signals are connected to the central system panel for monitoring continuously the system performance and the power flow for normal and fault situations.

Based on the above mentioned experimental setup, the transfer function of the power amplifier, which is the relationship of the input (command signal from the control PC) to the output (generated current signal) of the power amplifier, was obtained as a linear line with near zero offset. The transfer function of both the power amplifier and inductance filter card showed the same result.

Next, consider how to achieve the experimental speed-torque characteristics of the two motor drive systems, coupled by shaft, at different speeds. For the fixed rotational speed, the speed is kept constant as the dynamometer load is increased. When the torque reaches the maximum value, the speed begins to decrease just after the first motor has reached its maximum power output. Figure 4 shows the obtained speed-torque curves of using five different speeds depending upon applied current level, and all five curves present a similar tendency. Here notice that the ironless composite stator of the radial-flux PM motor was modified to provide an extra degree of freedom so the stator and rotor can be offset. It was observed that this axial motion to vary the offset (or overlap of the surface coverage between the rotor and stator) of the second motor affected the speed-torque characteristic of the first motor. Thus, three different offset cases with $0 \%, 50 \%$, and $100 \%$ overlaps were measured separately, and those characteristics were implemented into the control code as 3-D lookup table as shown in Figure 4.

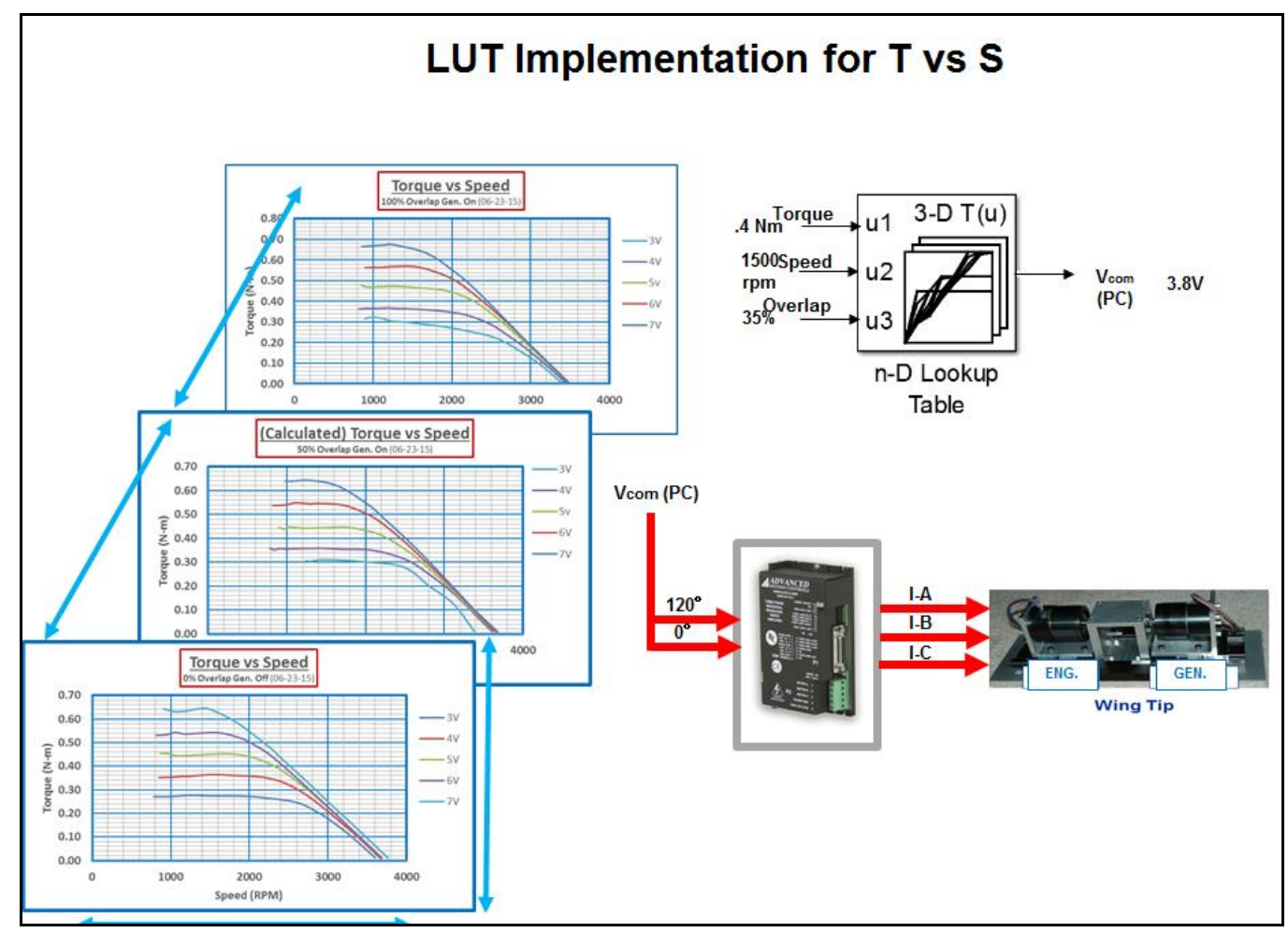

Figure 4. Dynamic characteristic of the motor drive system and its implementation using lookup table. 


\section{Turboshaft Engine-Generator Model and Motor-Based Emulator in HIL}



Figure 5. A turboshaft engine driving a generator model of two motor drives with a mechanical coupler.
The goal of this section is to develop a method by which an electric motor drive system can be controlled so as to emulate a gas turboshaft engine driving a generator, coupled by a shaft. The first motor and its drive system is programmed to mimic the steady-state and dynamic characteristics of a turboshaft engine, while the second motor and its drive system act as a generator and produce a torque load on the first motor. The control algorithm for the emulator has been developed and tested through a simulation model prior to implementation in the test rig.

Figure 5 shows the turboshaft engine-generator emulation system. In principle, the performance of the engine is emulated by setting the speed reference of the motor drive according to the performance predicted by a real-time model of the gas turbine engine. When the generator is driven by the engine, its speed can be affected by variations in the speed reference of the free turbine governor and the generator torque when changes of electrical load occur. Therefore, the

motor drive system includes closed-loop speed control to minimize the error between the reference signal for the motor controller from the engine observer and the actual motor speed.

For the first step, a gas turbine engine model must be been developed and replaced with the turbine engine observer. Here, Rowen's model ${ }^{5-12}$ for a heavy-duty gas turbine was employed for dynamic simulation, including fuel and control systems. Figure 6 shows the transfer function block diagram based on Rowen's model, and in the modeling simulation, a $48 \mathrm{MW}$ turbine base was used, and the associated parameter values were used. To check the performance of the two control loops, time domain simulations of several disturbances have been conducted. For various given torque loads, a speed controller modulates the fuel input so as to maintain the rotational speed constant. In addition, it is noticeable that the applied methodology can be applied for any size of gas turbines.

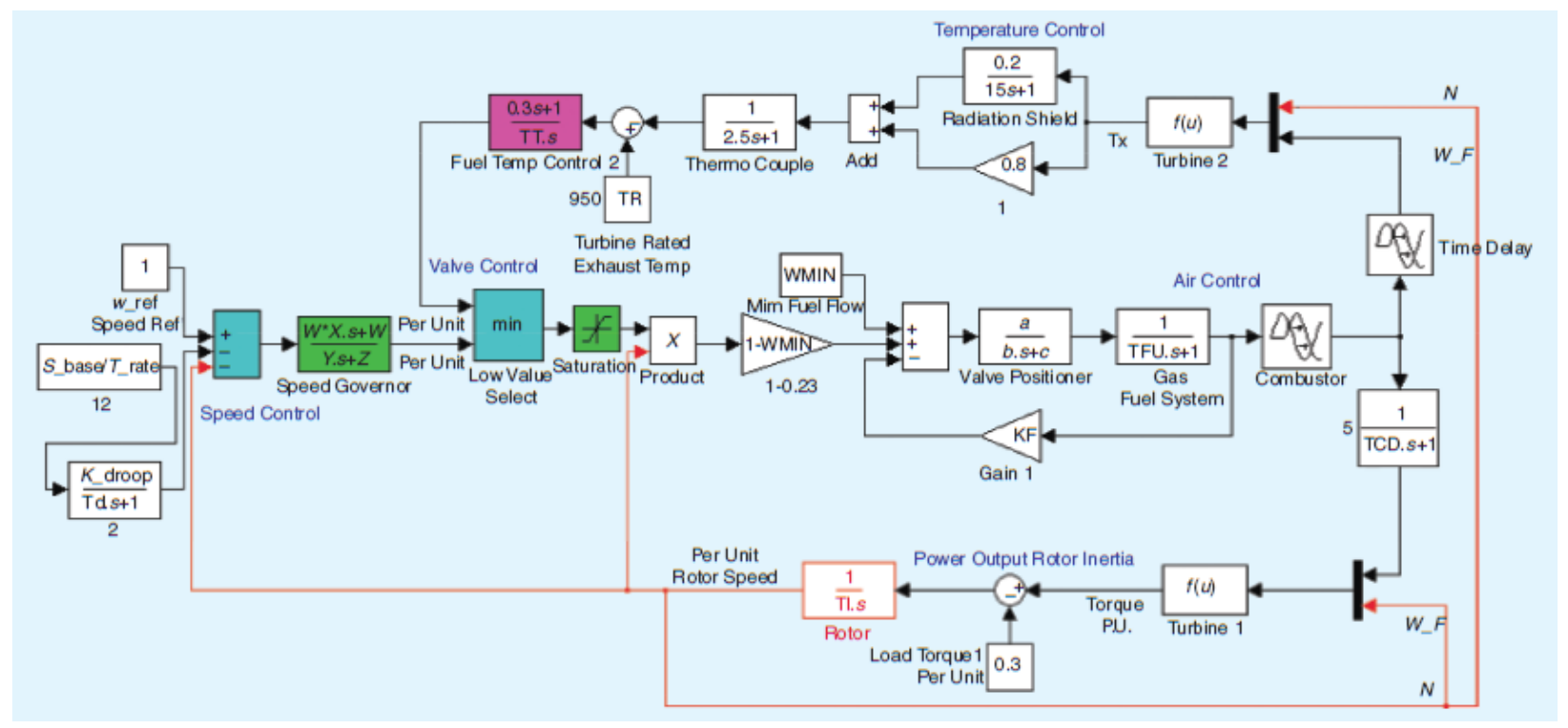

Figure 6. The gas turbine model in MATLAB/Simulink.

2017 American Institute of Aeronautics and Astronautics JPC 


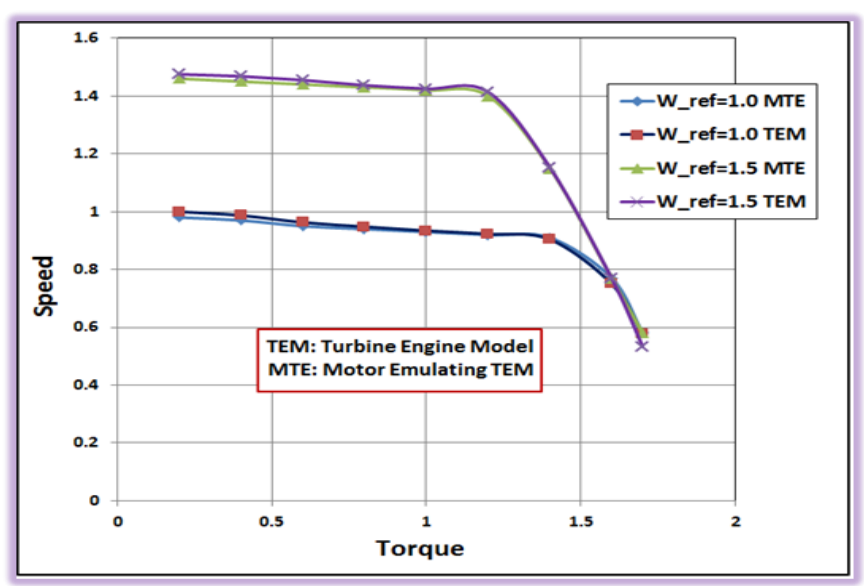

Figure 7. Speed versus torque characteristics of gas turbine model (open loop) and motor drive emulation in closed loon.
Next, it is described how to achieve the speedtorque characteristic of the gas turbine model at different speeds. For the fixed rotational speed, the speed is kept constant as the load is increased. When the torque reaches the maximum value, the speed begins to decrease as the fuel supply reaches its limit just after the engine has reached its maximum power output. Figure 7 shows the simulation results of using two different speeds, and the two curves present a similar tendency. This analytical model will be called a turbine engine observer in the following discussion.

Now, we will discuss implementation of gas turbine observer into motor-generator drive. It describes a method by which the first motor and drive can be controlled so as to emulate the steadystate and dynamic characteristics of the gas turbine engine model in Figure 6. This can be implemented

by inserting the engine observer block between the torque reference from the generator and the speed reference into the motor (see Figure 8). In such a setup, the first motor gets its speed reference from the model of the gas turbine engine, given the load torque from the second motor. This coupled model can emulate the speed regulated turbine engine and the torque regulated generator for step changes in commanded torque from the predefined flight path profiles. The signs of the electric torque and speed should be the same for the motor that emulates the turbine engine when it is driving. The torque and speed should be of opposite signs for the second motor that emulates the generator.

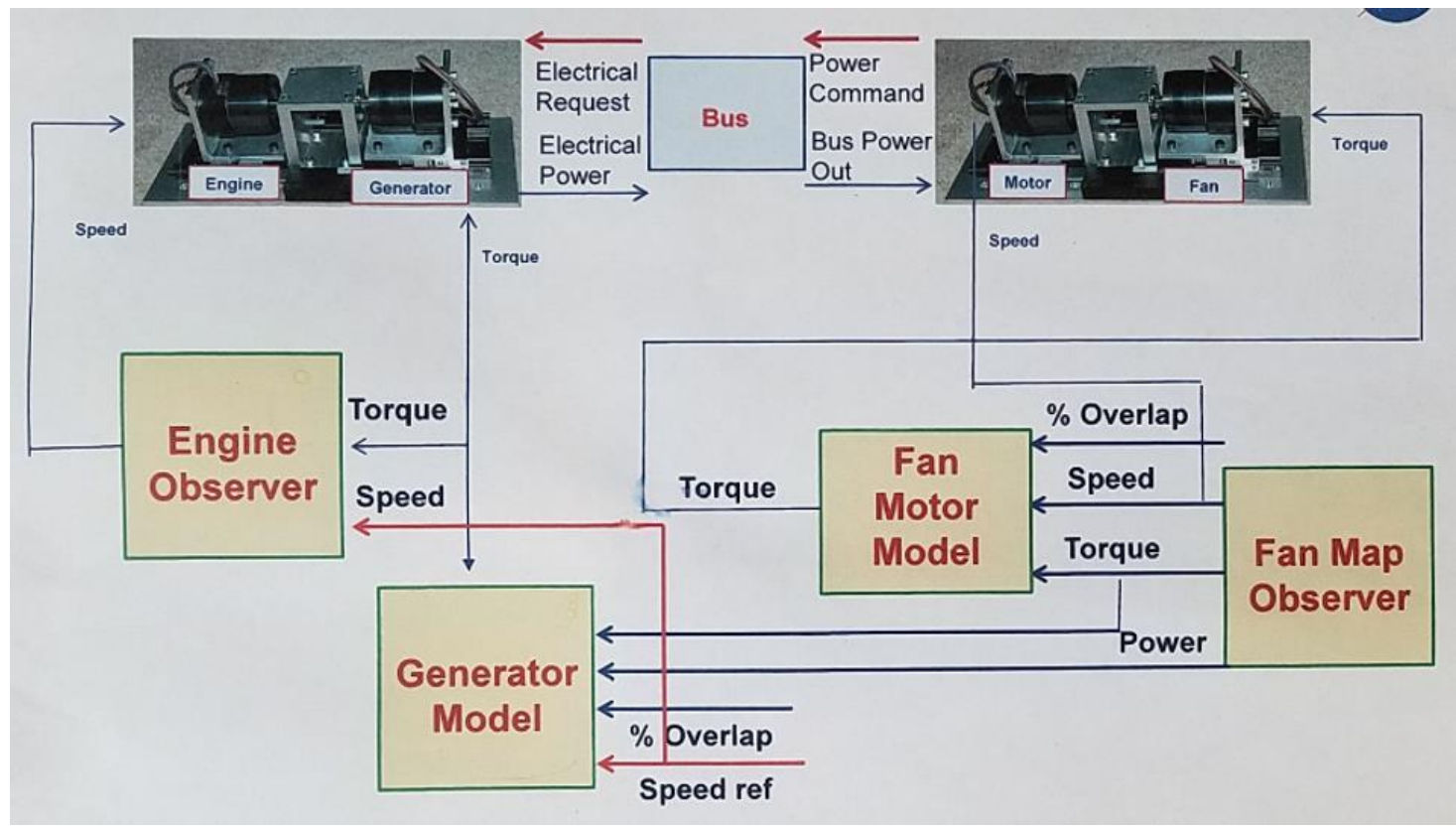

Figure 8. Power grid emulator and dSPACE control system in HIL.

The next step is to create a real-time observer for the gas turbine model and the generator model such that a practical hardware implementation can be realized. The generator model here is represented by a set of experimental speed-torque curves obtained in Figure 4. The inputs to the generator model are the \% of overlap, speed reference, and electrical request from the power and torque values from the fan observer (discussed in the following section) for various given flight condition, engine parameters, and predefined flight path profile. Notice that since the Thin 
Gap motor drive system is capable of up to $1.5 \mathrm{~kW}$, all variables associated with MW engine observer and fan observer were scaled down accordingly to be fit into the existing motor drive systems. For the purpose of real-time simulation, Matlab/Simulink and Real Time Workshop were used to generate $\mathrm{C}$ code for the observer, generator model, and the associated closed-loop control laws, and the executable control code was downloaded into the dSPACE control system for the hardware in the loop (HIL) implementation. The whole system model was tested in HIL simulation, and the results have shown that the controlled first motor and drive with speed closed-loop control is able to operate in accordance with the speed-torque characteristic of the turbine engine model.

\section{Propulsive Motor-Fan Model and Motor-Based Emulator in HIL}

The goal of this section is to develop a method by which the motor drive system, coupled by a shaft, emulating the propulsive motor-fan model, can be controlled to emulate the wound-rotor synchronous motor driving the fan that would be a load torque applied to the fan shaft. The reference torque can be obtained by given fan maps of specific model and corresponding flight conditions. The closed-loop torque-control algorithm for the emulator has been developed and tested through a simulation model in Matlab/Simulink prior to implementation in the test rig.

\section{A. Modeling of Fan Map}

Complete fan maps are either based on fan rig test results or are predicted by a special computer program. A fan map is important, since it is an integral part of predicting the performance of a gas turbine engine, both at design and off-design conditions. However, these maps are difficult to use in a computer simulation due to their steep gradients and multiple independent variables. Thus, beta maps were developed as a technique to reduce conventional component characteristic maps into a number of simpler maps. More maps are required for the beta format because

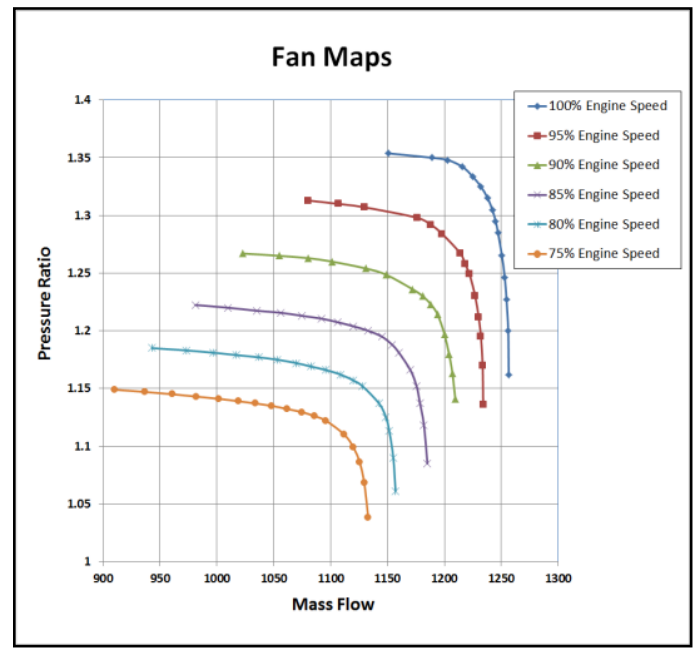

Figure 9. Fan map at high speed used in the simulation. they take the variables from a conventional map and split them into maps that contain only one dependent variable as a function of one independent variable used in generally corrected speed.

Figure 9 shows fan maps used in the simulation, which can generate an equivalent power level of a Boeing 787 GEnx fan at high speeds. This fan has the dependent variable pressure ratio $\left(P_{\text {exi }} / P_{\text {inlet }}\right)$ on the ordinate and the first independent variable, corrected mass flow, on the abscissa. The second independent variable, corrected speed, is shown as lines of constant corrected speed that extend from surge to choked conditions. Using the beta line technique, two sets of data can be achieved. One set of data would be the pressure ratio as a function of corrected speed. This collection of data would provide one beta line on the fan pressure ratio on the beta map. The second set of data would be the corresponding corrected mass flow as a function of corrected speed. The corrected mass flow data would also provide one beta line on the fan corrected mass flow on the beta map. By collecting data for a number of pressure ratios and corrected

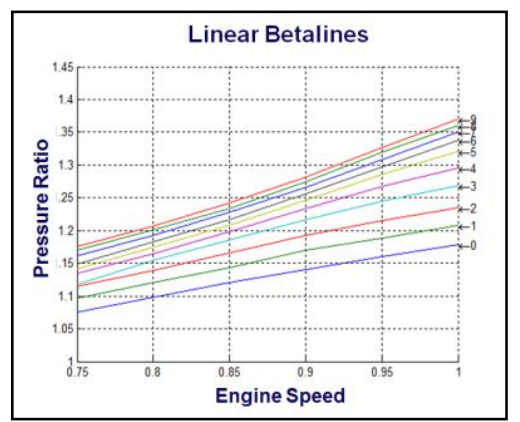

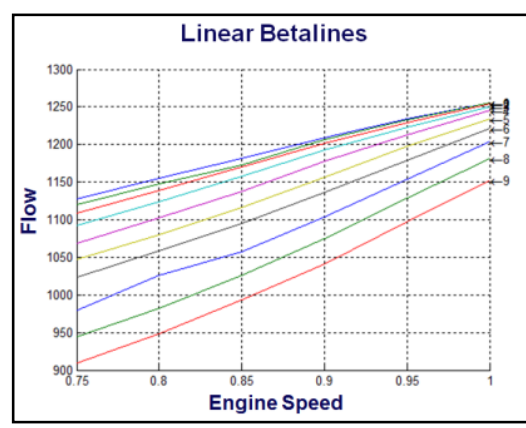

mass flow beta lines as a function of corrected speed, a mass flow beta map versus speed and a pressure ratio beta map versus speed can be obtained from the original fan maps. Figure 10 shows the airflow beta map and pressure ratio beta map necessary for the computer simulation. These two beta maps have been implemented into the simulation code as lookup tables accordingly.

Figure 10. Linear betalines. A) Flow vs. engine speed. b) Pressure ratio vs. engine speed. 


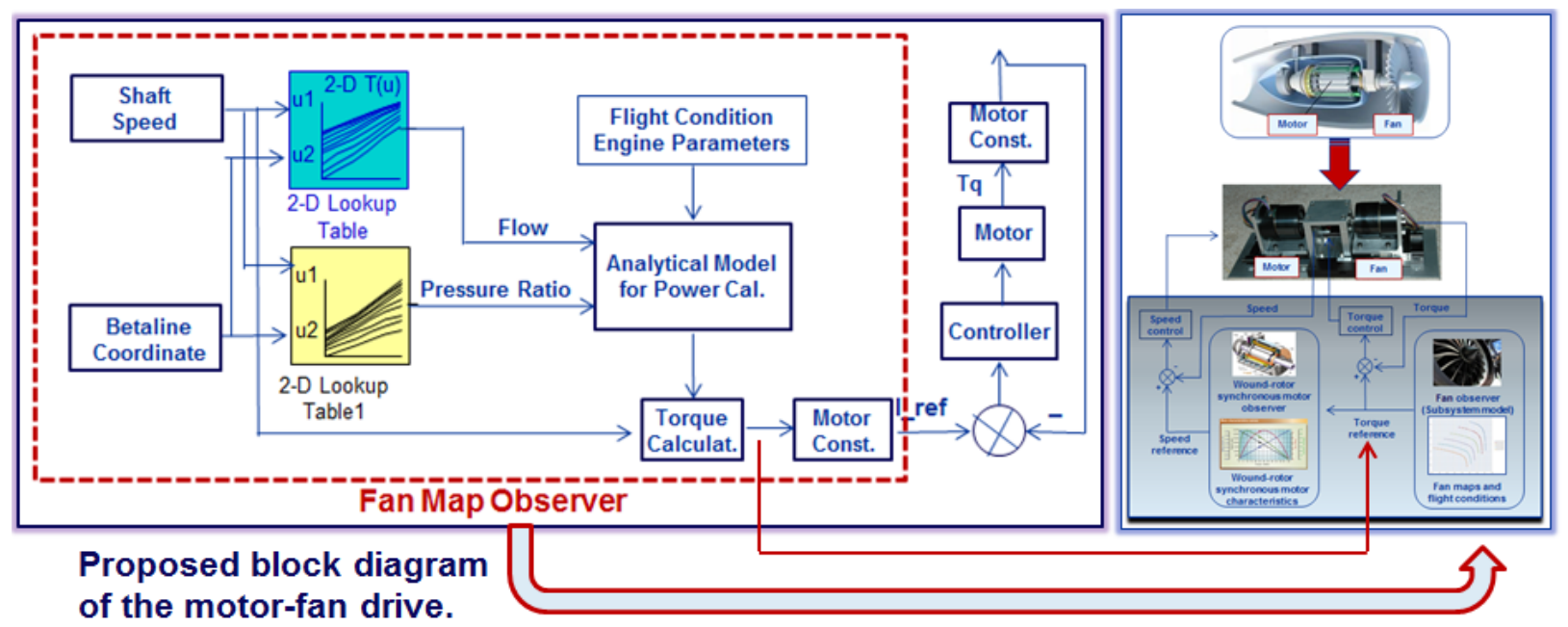

Figure 11. A block diagram of the motor-fan drive.

Figure 11 shows a block diagram for the motor-fan drive system. First, engine speed and beta coordinates go to the lookup table blocks to predict the values of flow and pressure ratio. Then, these two values in conjunction with flight conditions and engine parameters go to the analytical model for the fan power out calculation, which is the power delivered to the air by fan. This output power with the given engine speed go to the torque block to calculate the torque load supplied to the fan shaft. Through the motor constant block, the current for the fourth motor to generate the required torque is eventually obtained. This current from the fan observer becomes a reference signal for the closed-loop control of the current of the second motor. This current is regulated to match with the desired torque by the proportional-integral controller, so that the motor torque is equal to the output torque of the simulated fan.

\begin{tabular}{|c|c|}
\hline Altitude & Up to $35000 \mathrm{ft}$ \\
\hline Mach number & Up to 0.9 \\
\hline Density & $0.41-1.15 \mathrm{~kg} / \mathrm{m}^{3}$ \\
\hline Engine speed & $75 \%-100 \%$ of the maximum speed \\
\hline Mass flow rate & $412-566 \mathrm{~kg} / \mathrm{s}$ \\
\hline Pressure ratio & $1.04-1.35$ \\
\hline Absolute pressure & $(2.6-10) \times 10^{4} \mathrm{~N} / \mathrm{m}^{2}$ \\
\hline Fan efficiency & $0.96-0.98$ \\
\hline
\end{tabular}

Table 1. Flight conditions and engine parameters for predefined flight profiles.

For modeling of the fan power out calculation, several modeling techniques have been tested in order to investigate which could generate the best prediction, and the Wayne Sexton's fan power ${ }^{13}$ out formula

has been selected for the simulation work. Note that the fan efficiency can be obtained similarly from the given fan maps, but its value is assumed in this study, omitting its long process. The flight conditions and engine parameters for given flight path profiles used in the simulation are described in Table I.

Similar to the motor drive system model described in the section III, the same two-motor drive system that consists of coupling an AC motor drive model to another identical AC motor drive model, coupled by a shaft, was used to mimic a coupled motor-fan. The ac motor drive is a three-phase synchronous motor-based drive that can simulate a wound-rotor synchronous motor. The ironless composite stator of the Thin Gap is designed to travel along the rotating axis so that the main flux can be varied by changing the surface coverage between the rotor and stator. This feature allows the PM motor drive system to more closely emulate a wound-rotor synchronous machine

The second motor drive system can imitate a fan that would generate various load torque conditions. Hence, this coupled model can emulate the speed regulated wound-rotor motor and the torque regulated fan. The signs of the ac electric torque and speed should be the same for the motor that mimics the wound-rotor synchronous motor when it is driving. The torque and speed should be of opposite signs for the motor that simulates the fan. 


\section{B. Implementation of Fan Map Observer into Motor-Fan Drive}

This section describes a method by which the motor and its drive, acting as a fan, can be controlled so as to emulate the characteristics of the fan maps and flight conditions described. This observer block can generate a load torque reference, and through a motor constant block, its signal is converted into a current reference into the closedloop current control block for the second motor. In such a setup, the first motor drive gets its speed reference from the observer model of a wounded-rotor synchronous motor under the load torque from the second motor. The whole system model is tested in simulation, and the simulation results have shown that the characteristics of fan maps and operating conditions can be achieved (less than $1 \%$ steady-state error) by means of the motor and its drive with torque closed-loop control.

Similar to the real-time implementation procedures described in the section III, a real-time observer for the fan map and the motor-fan model such that a practical hardware implementation can be realized. The fan motor model and driving motor model here are represented by a set of experimental speed-torque curves, respectively, obtained in Figure 4 . The inputs to the fan motor model are the \% of overlap, speed, and torque values from the fan observer for various given flight condition, engine parameters, and predefined flight path profile. Again, notice that since the Thin Gap motor drive system is capable of up to $1.5 \mathrm{~kW}$, all variables associated with MW fan map observer was scaled down accordingly to be fit into the existing motor drive systems. Through the same process shown in the section III, the executable control code was downloaded into the dSPACE control system for the hardware in the loop (HIL) implementation. The whole system model was tested in HIL simulation, and the results have shown that the controlled second motor and drive with torque closed-loop control is able to operate in accordance with the fan map observer.

\section{Turbo-shaft Engine Driven Fan (Turbofan Engine) Model and Motor-Based Emulator in HIL}

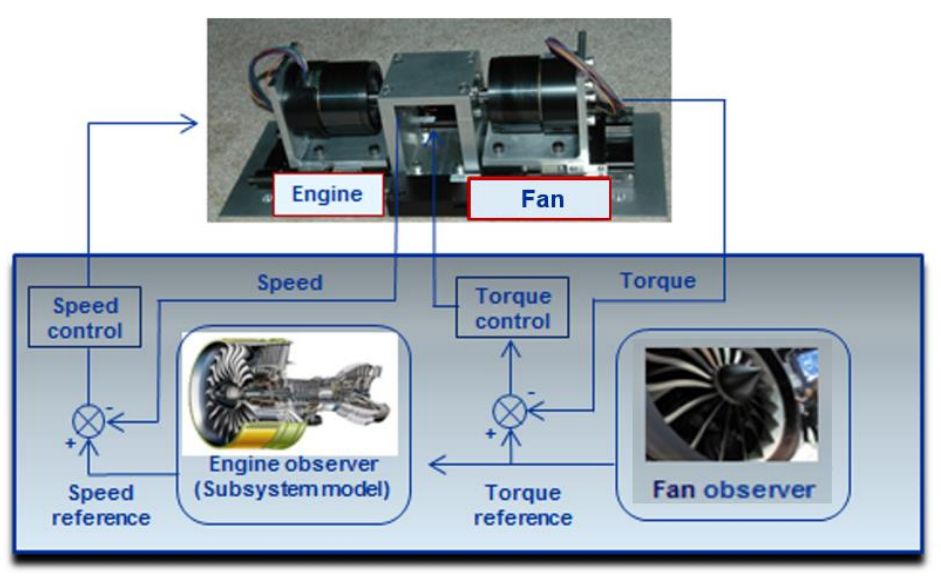

Figure 12. A turboshaft engine driving a fan model of two motor drives with a mechanical coupler.

Also, the same set of motor drive systems was used to emulate a turbo-shaft engine driven fan (turbofan engine) emulation. In this case, the first motor and its drive system mimicked the speed-torque characteristics of the gas turbine engine, while the second motor and drive acted as a load torque on the turboshaft motor to emulate the fan maps and flight conditions.

Similar to the previous procesures described in the sections III and IV, a realtime observers for the gas turbine model and the fan model such that a practical hardware implementation can be realized. The turboshaft engine model and the fan model are represented by a set of experimental speedtorque curves obtained in Figure 4. The whole system model was tested in HIL simulation, and the results have shown that the controlled first motor and drive with speed closed-loop control is able to operate in accordance with the speed-torque characteristic of the turbine engine model, and the controlled second motor and drive with torque closed-loop control is able to operate in accordance with the fan map observer.

\section{Propulsion Electric Grid Emulator Setup}

The system has been expanded to multiple power grids that consist of two engine/generator sets and three motor/fan sets as shown in Figure 13. This inexpensive simulator will emulate two turbine engines and three fans, interconnected by generators, rectifiers, a DC bus, inverters and fan drive motors. A TeDP system utilizing all ten motors and drives with closed-loop controllers makes it possible to emulate a representative part of the TeDP powertrain. A Rolls-Royce fail-safe code of $\mathrm{TeDP}^{14}$ for future hybrid-wing-body electric airplane is also implemented into the propulsion electric grid simulator (PEGS) as shown in Figure 14. 


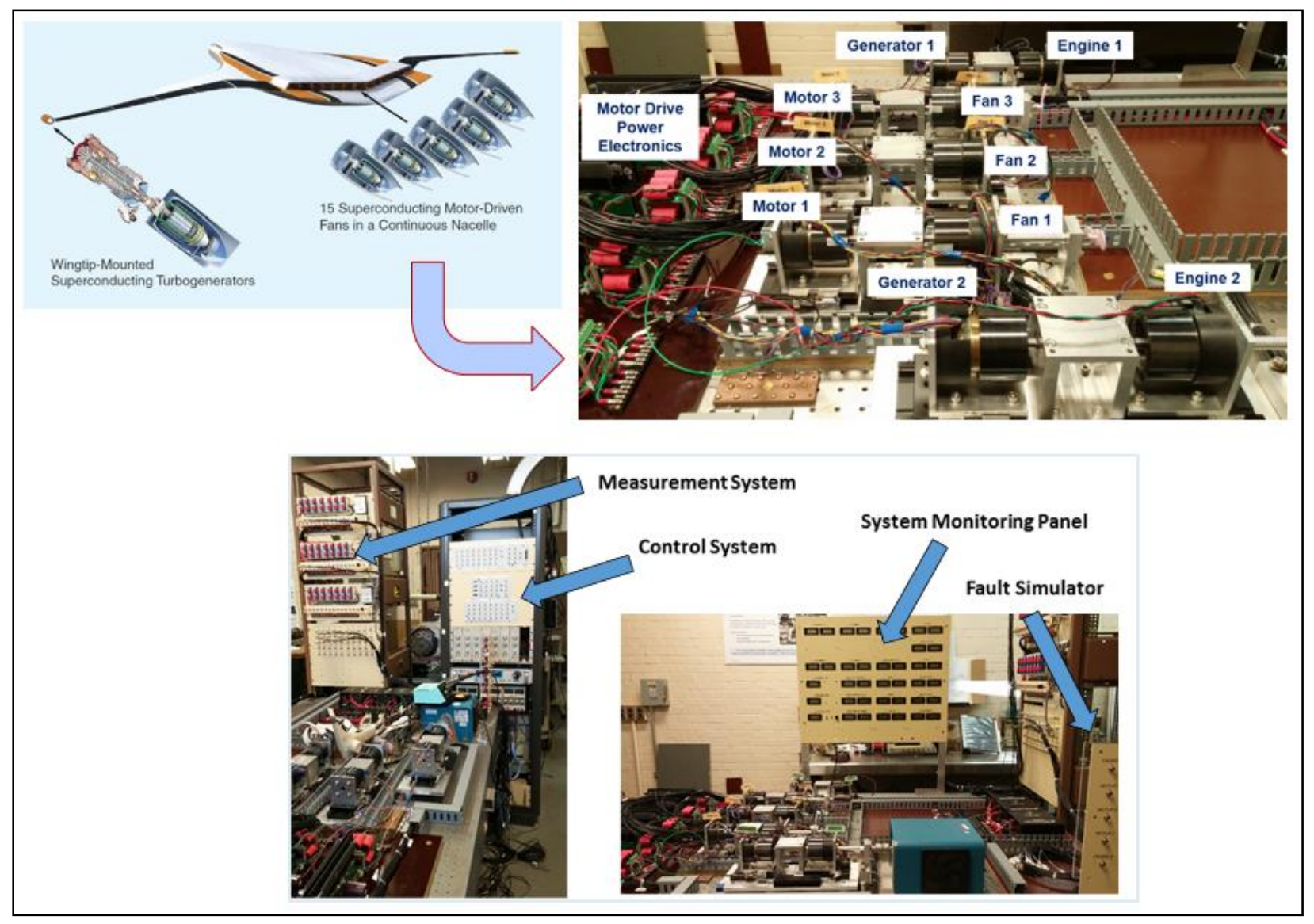

Figure 13. Experimental setup of Propulsion Electric Grid Simulator (PEGS) implementing N3-X hybrid wing-body aircraft with a TeDP system.

\section{Summary}

In this paper, we have presented (a) the experimental dynamic characterization procedure of the two motor drive systems, coupled by a shaft, and its implementation technique into the control code using a 3-D lookup table, (b) the development of three powertrain emulations of the TeDP system to mimic a turbo-shaft engine driven generator, motor driven fan, and turbo-shaft driven fan (turbofan engine), and (c) the subscale experimental system to emulate a TeDP system utilizing all ten motors and drives with closed-loop controllers. This work has proven that it is possible to emulate a representative part of the TeDP powertrain.

The operation principle behind the technology is that all rotating components can be represented by torque and speed curve sets. Simulation results have shown that their dynamic characteristics can be implemented by using the closed-loop control of the electric motor drives. Planned future study includes (1) characterizing the experimental interaction of the many electrical components, (2) testing and evaluating parametric performance, (3) validating system model analyses and predictions, and (4) analyzing transient response (including faults), grid stability, and internal autonomy experiments. 


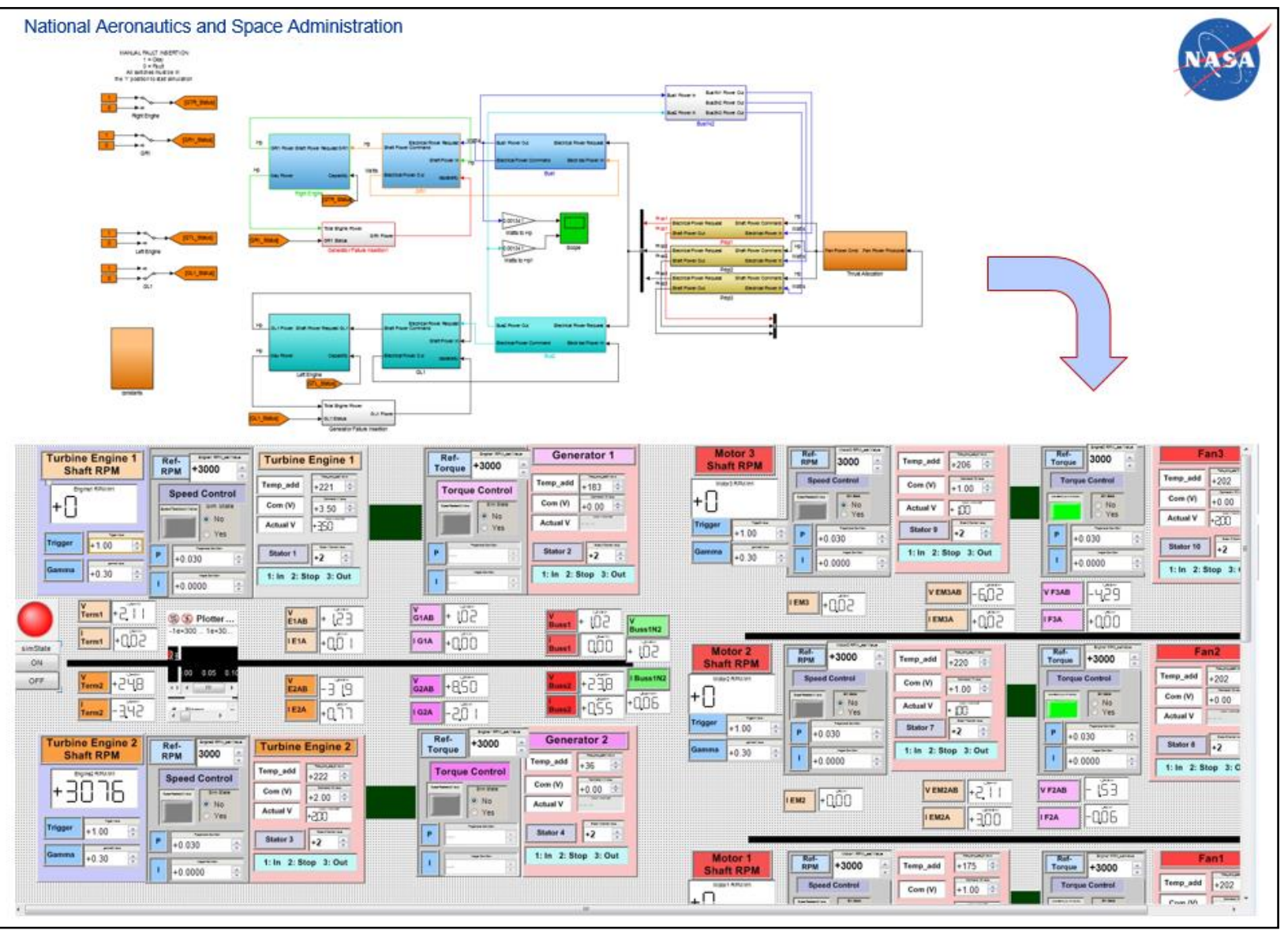

Figure 14. Experimental setup of Propulsion Electric Grid Simulator (PEGS) implementing Rolls-Royce fail-safe code of TeDP.

\section{Acknowledgments}

This work was in full support of the Electrified Aircraft Propulsion (EAP) under Advanced Air Transportation Technology (AATT) Project at NASA Glenn Research Center. The authors thank to Mr. Ben Ebihara at Vantage Partners Co. for his great efforts in designing and fabricating the coupled motor assemblies.

\section{References}

${ }^{1}$ Choi, B., Morrison, C., Dever, T., and Brown, G., "Propulsion Electric Grid Simulator (PEGS) for Future Turboelectric Distributed Propulsion Aircraft," AIAA Propulsion and Energy Forum, July 28-30, 2014, Cleveland, Ohio.

${ }^{2}$ Kim, H. D., Brown, G. V., and Felder, J. L., "Distributed Turboelectric Propulsion for Hybrid Wing Body Aircraft," International Powered Lift Conference, London, England, July 22-24, 2008.

${ }^{3}$ Felder, J. L., Brown, G. V., Kim, H. D., and Chu, J., "Turboelectric Distributed Propulsion in a Hybrid Wing Body Aircraft," ISABE-2011-1340, 2011.

${ }^{4}$ Brown, G. V., "Efficient Flight-Weight Electric Systems," 2012 Technical Conference, NASA Fundamental Aeronautics Program, Subsonic Fixed Wing Project, Cleveland, Ohio, March 13-15, 2012.

${ }^{5}$ Akpolat, Z., Asher, G., and Clare, J., "Experimental dynamometer emulation of nonlinear mechanical loads," IEEE Transactions on Industry Applications, vol. 35, 1999, pp., 1367, 1373.

${ }^{6}$ Kojabadi, H., Chang, L., and Boutot, T., "Development of a novel wind turbine simulator for wind energy conversion systems using an inverter-controlled induction motor," IEEE Transactions on Energy Conversion, vol. 19, 2004, pp., 547, 552.

${ }^{7}$ Correa, B. A., Smith, A., Jiang, W., and Dougal, R. A., "Gas turbine emulator for testing of high-speed generators," IEEE SoutheastCon 2010, 2010, pp., 226, 229. 
${ }^{8}$ Voigt, K., “A control scheme for a dynamical combustion engine test stand," International Conference on Control, vol. 2 , 1991, pp., 938, 943.

${ }^{9}$ Yee, S. K., Milanovic, J., and Hughes, F., "Overview and Comparative Analysis of Gas Turbine Models for System Stability Studies," IEEE Transactions on Power Systems, vol. 23, 2008, pp., 108, 118.

${ }^{10}$ Hannett, L. N., and Khan, A. H., "Combustion turbine dynamic model validation from tests," IEEE Transactions on Power Systems, vol. 8, 1993, pp., 152, 158.

${ }^{11}$ Asgari, H., Chen, X. Q., and Sainudiin, R., "Considerations in modelling and control of gas turbines - a review," $2^{\text {nd }}$ International conference on control, instrumentation, and Automation (ICCIA 2011), Dec.27-29 2011, Shiraz, Iran.

${ }^{12}$ Rowen, W. I., "Simplified mathematical expressions of heavy duty gas turbines," Transactions of the ASME Journal of engineering for Power, vol. 105, 1983, pp., 865, 870.

${ }^{13}$ Sexton, W. R., A Method to Control Turbofan Engine Starting by Varying Compressor Surge Valve Bleed, Master thesis, Dept. of mechanical engineering, Virginia Tech, May 2001.

${ }^{14}$ Armstrong, M., Ross, C., Phillips, D., and Blackwelder, M., Stability, Transient Response, Control, and Safety of a Highpower Electric Grid for /CR-2013-217865, E-18658, June 01, 2013. 